\title{
A Primary Trisomic for Chromosome 3 in a 6-Rowed Barley
}

\author{
K. Das and S. C. Kundu \\ Department of Genetics and Plant Breeding \\ Banaras Hindu University \\ Varanasi, India
}

Received May 30, 1971

Work on isolation and identification of trisomics from interchange-heterozygotes in a six-rowed cultivated barley, variety $\mathrm{K}-12$, has been in progress for some time at this laboratory and a few primary, interchange- and tertiary trisomics have been isolated from irradiated material (Das and Bhowmik 1971, Das and Goswami 1967, Das and Srivastava 1968, 1969). This paper describes the gross morphology and cytogenetic behaviour of a trisomic isolated from gamma irradiated barley seeds. The extra chromosome of the trisomic was identified from cytological study of the $F_{1}$ hybrids between the trisomic and a set of Burnham's translocation testers. Transmission rate of the extra chromosome through egg and pollen was determined. An experiment was also carried out to determine whether lighter seeds of trisomics throw more trisomic progeny or not.

\section{Material and methods}

Selfed seeds from a cytologically checked trisomic plant were space planted in field in November 1968. Pollen and ovule sterility were determined. Microsporocytes from phenotypically distinct plants were fixed in freshly prepared $1: 3$ aceticalcohol for 24 hours and stored in a refrigerator in 70 per cent alcohol. All chromosomal studies were made in temporary smear preparations stained with 1.5 per cent aceto-propiono-carmine. Microphotographs were taken from sealed preparations. To identify the extra chromosome, trisomic plants as female parents were crossed with Burnham's translocation tester set T 1-2a, T 1-6d, T 2-4a, T 3-5b, $\mathrm{T} 4-5 \mathrm{a}$ and $\mathrm{T}$ 6-7a. To study the transmission rates of the extra chromosome through egg and pollen, trisomic plants were selfed and reciprocally crossed with normal diploids. In the next season, hybrid seeds were space planted in field.

To determine whether weak and lighter seeds of trisomic plants throw more trisomic progeny or not, selfed seeds of trisomic plants were separated into two lots. The seeds of the first lot were shrivelled, thin, small and light while in the other lot they were bold, healthy and normal in appearance. In the lighter group 20-seed weight varied from 0.59 to $0.72 \mathrm{gm}$ Seeds were sown in petridishes and the germinated seeds were transplanted in field. After five weeks the seedlings were identified as diploids or trisomics on the basis of their external morphology and later confirmed cytologically. Transmission rates of the extra chromosome in these two groups and reciprocally crossed hybrids were recorded. After analysing cytologically the $F_{1}$ between the trisomic and translocation testers the chromosome involved in the trisomic plant was determined. 


\section{Results}

Gross morphology: When the plants growing in the field were carefully examined some plants appeared different from the normal plants approximately five weeks after germination. The leaves of these plants were more narrow than the normal plants. The leaf margins were rolled and were light green in colour.
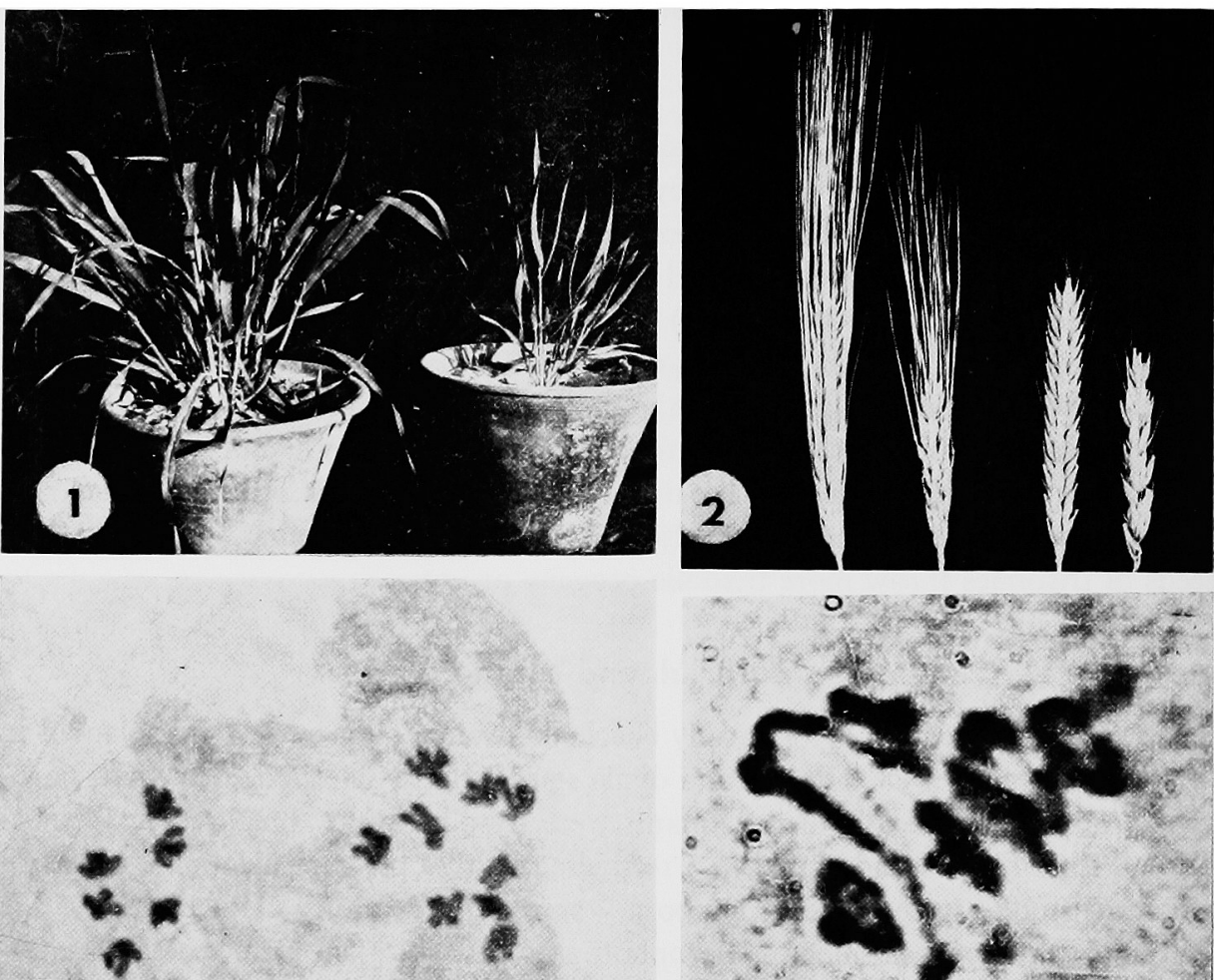

3
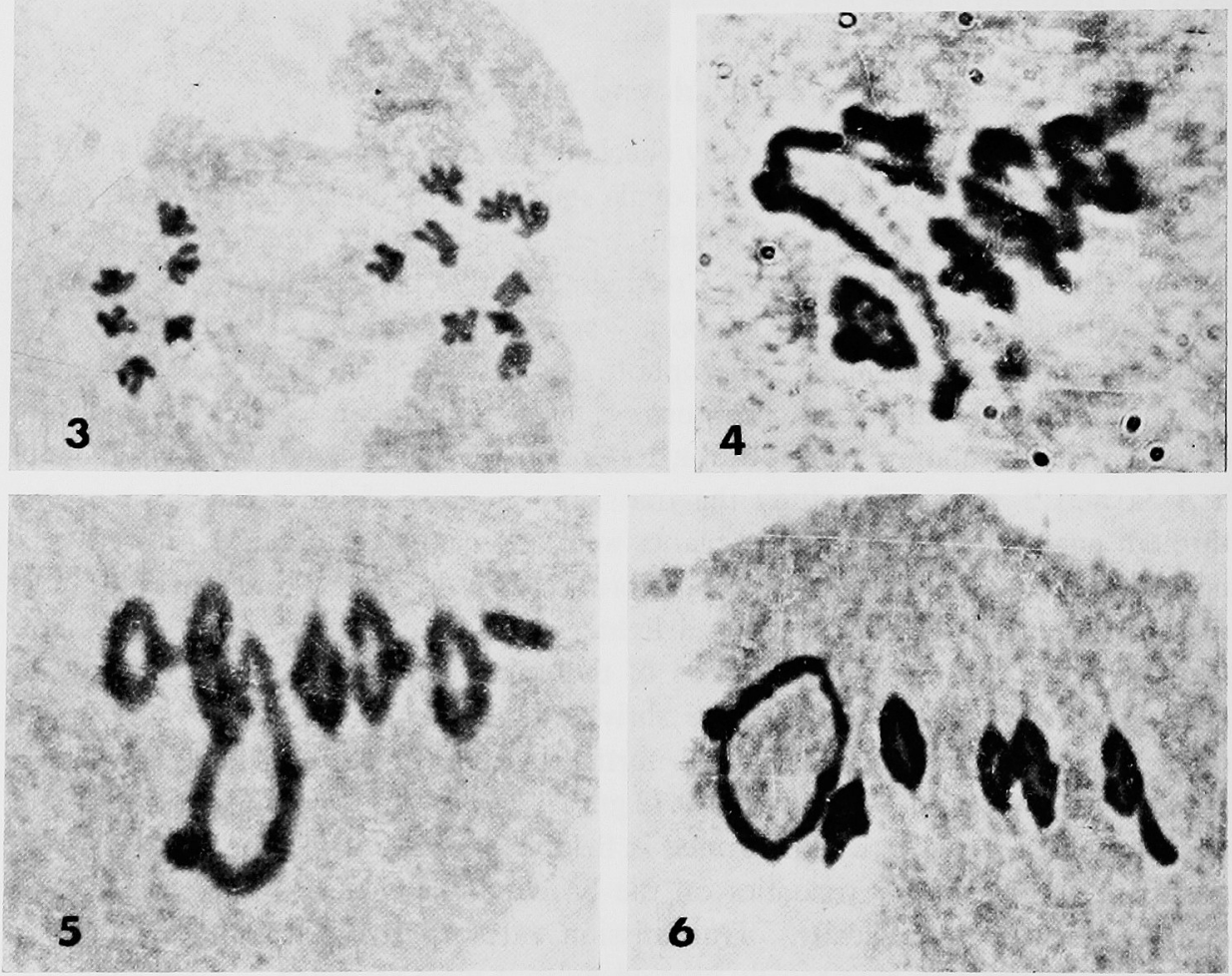

Figs. 1-6. 1, trisomic and normal plants. 2, spikes of normal and trisomic plants. 3, 9:6 separation at anaphase I. $4,1^{\mathrm{V}}(1$ bivalent attached with trivalent $)+5^{\mathrm{II}} .5, \mathrm{O}_{4}+5^{\mathrm{II}}+{ }^{\mathrm{I}} 1.6$, $\mathrm{O}_{4}+4^{\mathrm{II}}+1^{\mathrm{III}}$. 
They were also more thin and short. The lower leaves matured earlier than in the normal plants (Fig. 1). Spikes were deformed, short and narrow and were not compact (Fig. 2). Seeds were small in size. The range of pollen sterility in these plants was 15.10 to 36.40 per cent. Ovule sterility varied between 15.14 to 68.51 per cent.

Cytology: Meiotic study of the sporocytes of the plants which were strikingly different in external morphology from the normal plants showed the presence of an extra chromosome.

Table 1. Frequency of different chromosome association at metaphase $I$ in trisomic plants

\begin{tabular}{c|c|c|c|c}
\hline \hline \multirow{2}{*}{$\begin{array}{c}\text { Plant } \\
\text { number }\end{array}$} & \multirow{2}{*}{$\begin{array}{c}\text { No. of trisomic } \\
\text { cells analyzed }\end{array}$} & \multicolumn{3}{|c}{ Chromosome associations } \\
\cline { 3 - 5 } & & $7_{\mathrm{II}}+1_{\mathrm{I}}$ & $6_{\mathrm{II}}+1_{\mathrm{III}}$ & $6_{\mathrm{II}}+3_{\mathrm{I}}$ \\
\hline $1381-8$ & 62 & 36 & 26 & - \\
$"-17$ & 73 & 30 & 42 & 1 \\
$"-18$ & 38 & 24 & 14 & - \\
$"-22$ & 54 & 22 & 30 & 2 \\
$"-33$ & 40 & 16 & 24 & - \\
$"-47$ & 90 & 38 & 52 & - \\
\hline Total & 357 & 166 & 188 & 3 \\
\hline Mean per cent & & 46.50 & 52.66 & 0.84 \\
\hline
\end{tabular}

Table 2. Types of triyalents at metaphase I in trisomic plants

\begin{tabular}{|c|c|c|c|c|c|c|c|c|c|}
\hline \multirow{3}{*}{$\begin{array}{c}\text { Plant } \\
\text { number }\end{array}$} & \multirow{3}{*}{$\begin{array}{c}\text { Cells } \\
\text { analysed }\end{array}$} & \multicolumn{8}{|c|}{ Chromosome associations } \\
\hline & & \multicolumn{2}{|c|}{ Chain } & \multicolumn{2}{|c|}{ V-shaped } & \multicolumn{2}{|c|}{ Y-Shaped } & \multicolumn{2}{|c|}{ Q-Shaped } \\
\hline & & No. & $\begin{array}{l}\text { Per } \\
\text { cent }\end{array}$ & No. & $\begin{array}{l}\text { Per } \\
\text { cent }\end{array}$ & No. & $\begin{array}{l}\text { Per } \\
\text { cent }\end{array}$ & No. & $\begin{array}{l}\text { Per } \\
\text { cent }\end{array}$ \\
\hline $1381-8$ & 26 & 17 & 65.38 & 5 & 19.23 & 4 & 15.38 & - & - \\
\hline$"-17$ & 42 & 14 & 33.33 & 11 & 26.19 & 9 & 21.42 & 8 & 19.04 \\
\hline$"-18$ & 14 & 10 & 71.42 & 3 & 21.42 & 1 & 7.14 & - & - \\
\hline$"-22$ & 30 & 14 & 46.66 & 7 & 23.33 & 4 & 13.33 & 5 & 15.66 \\
\hline$"-33$ & 24 & 9 & 37.50 & 7 & 29.16 & 5 & 20.83 & 3 & 12.50 \\
\hline$"-47$ & 52 & 21 & 40.38 & 18 & 34.61 & 12 & 23.07 & 1 & 1.92 \\
\hline Total & 188 & 85 & & 51 & & 35 & & 17 & \\
\hline \multicolumn{2}{|c|}{ Mean per cent } & & 45.21 & & 27.13 & & 18.61 & & 9.04 \\
\hline
\end{tabular}

At diakinesis and metaphase $\mathrm{I}$, the extra chromosome showed different types of association such as $7_{\mathrm{II}}+1_{\mathrm{I}}$ and $6_{\mathrm{II}}+1_{\mathrm{III}}$ and $6_{\mathrm{II}}+3_{\mathrm{I}}$. While $7_{\mathrm{II}}+1_{\mathrm{I}}$ and $6_{\mathrm{II}}+$ $1_{\text {III }}$ were equally frequent, the frequency of $6_{\text {II }}+3_{I}$ was very low (Table 1 ).

The trivalents were a chain of three, V, Y, and $Q$ shaped or frying pan type (Table 2). As evident from Table 2, Q shaped or frying pan types were lower in 
frequency than other types of trivalents. At anaphase I trisomic plants showed 7-7, 7-8, 7-1-7 and 9-6 separation (Fig. 3). The frequency of different types of anaphasic separation in different trisomic plants is shown in Table 3.

Table 3. Number and per cent of cells showing different types of separation in anaphase $I$ in trisomic plants

\begin{tabular}{|c|c|c|c|c|c|c|c|c|c|}
\hline \multirow{3}{*}{$\begin{array}{l}\text { Plant } \\
\text { number }\end{array}$} & \multirow{3}{*}{$\begin{array}{c}\text { Cells } \\
\text { analysed }\end{array}$} & \multicolumn{8}{|c|}{ Anaphasic separation } \\
\hline & & \multicolumn{2}{|c|}{$7-7$} & \multicolumn{2}{|c|}{$7-8$} & \multicolumn{2}{|c|}{$7-1-7$} & \multicolumn{2}{|c|}{$9-6$} \\
\hline & & No. & $\begin{array}{l}\text { Per } \\
\text { cent }\end{array}$ & No. & $\begin{array}{l}\text { Per } \\
\text { cent }\end{array}$ & No. & $\begin{array}{c}\text { Per } \\
\text { cent }\end{array}$ & No. & $\begin{array}{l}\text { Per } \\
\text { cent }\end{array}$ \\
\hline $1381-8$ & 16 & 3 & 18.75 & 10 & 62.50 & 1 & 6.25 & 2 & 12.50 \\
\hline$" \quad-17$ & 35 & 6 & 17.14 & 25 & 71.42 & 4 & 11.42 & - & - \\
\hline$"-18$ & 42 & 9 & 21.42 & 28 & 66.66 & - & - & 5 & 11.90 \\
\hline$"-22$ & 51 & 5 & 9.80 & 37 & 72.54 & 8 & 15.68 & 1 & 1.96 \\
\hline$"-33$ & 22 & 3 & 13.63 & 11 & 50.00 & 4 & 18.18 & 4 & 18.18 \\
\hline$"-47$ & 28 & - & - & 19 & 67.85 & 5 & 17.85 & 4 & 14.28 \\
\hline Total & 194 & 26 & & 130 & & 22 & & 16 & \\
\hline \multicolumn{2}{|l|}{ Mean per cent } & & 13.40 & & 67.01 & \multicolumn{2}{|r|}{11.34} & & 8.24 \\
\hline
\end{tabular}

Transmission of the extra chromosome: Data on transmission rates of the extra chromosome through pollen and egg are summarised in Table 4. It was observed that transmission rate was 26.30 through egg whereas through pollen it was nil. However, in the selfed seeds 39.09 per cent of trisomic plants was observed in lighter seed weight lot while in the heavier lot transmission was 22.75 per cent.

Table 4. Transmission frequencies of trisomic plants in progenies from $(2 n+1) \times(2 n),(2 n) \times(2 n+1)$ and $(2 n+1)$ selfed

\begin{tabular}{|c|c|c|c|c|}
\hline \multirow{2}{*}{ Types of cross } & \multirow{2}{*}{$\begin{array}{l}\text { Total no. } \\
\text { of plants }\end{array}$} & \multirow{2}{*}{$(2 n)$} & \multicolumn{2}{|c|}{$(2 n+1)$} \\
\hline & & & Number & Per cent \\
\hline$(2 n+1) \times(2 n)$ & 53 & 39 & 14 & 26.30 \\
\hline$(2 n) \times(2 n+1)$ & 35 & 35 & - & - \\
\hline $\begin{array}{l}(2 \mathrm{n}+1) \text { selfed: } \\
20 \text {-seed weight } \\
\text { below } 0.72 \mathrm{gm}\end{array}$ & 133 & 81 & 52 & 39.09 \\
\hline $\begin{array}{l}20 \text {-seed weight } \\
\text { above } 0.72 \mathrm{gm}\end{array}$ & 186 & 146 & 43 & 22.75 \\
\hline
\end{tabular}

Identification of the extra chromosome: The results of chromosomal configurations of hybrids between trisomic plants and the set of translocation testers are presented in Table 5.

Association of chromosomes in trisomic $F_{1}$ hybrids between the $2 n+1$ and the testers T 1-2a, T 4-5a, T 1-6d, T 2-4a and T 6-7a showed the presence of $\odot_{4}+1_{I I I}+4_{\text {II }}$ (Fig. 6) which indicates that the extra chromosome was not 1, 2, 4, 5,6 or 7 . The cross $(2 n+1) \times(T 3-5 b)$ showed $1_{v}+5_{\text {II }}$ (Fig. 4) at metaphase I indicating that the extra chromosome may be either 3 or 5 . However, the cross 
$(2 n+1) \times(T 4-5 a)$ did not reveal any pentavalent which suggested that chromosome 5 common to the testers $\mathrm{T} 3-5 \mathrm{~b}$ and $\mathrm{T} 4-5 \mathrm{a}$ is not the extra chromosome involved in the trisomic plants. The result, therefore, indicates that chromosome 3 is the extra chromosome in the trisomic plant.

Table 5. Per cent of chromosome association in trisomic $F_{1}$ hybrids between trisomic and the translocation testers

\begin{tabular}{c|c|c|c|c|c}
\hline Testers & $1 \odot_{4}+1_{\mathrm{III}}+4_{\mathrm{II}}$ & $1 \odot_{4}+1_{\mathrm{I}}+5_{\mathrm{II}}$ & $7_{\mathrm{II}}+1_{\mathrm{I}}$ & $6_{\mathrm{II}}+1_{\mathrm{III}}$ & $1_{\mathrm{V}}+5_{\mathrm{II}}$ \\
\hline T 1-2a & 59.52 & 40.48 & - & - & - \\
T 1-6d & 52.18 & 47.82 & - & - & - \\
T 2-4a & 26.66 & 53.34 & 13.33 & 6.66 & - \\
T 3-5b & - & 34.66 & 14.66 & 9.33 & $41.33^{*}$ \\
T 4-5a & 20.00 & 41.80 & 10.90 & 27.29 & - \\
T 6-7a & 68.51 & 31.48 & - & - & - \\
\hline
\end{tabular}

* Chromosome 3 identified as extra chromosome.

\section{Discussion}

Since the work on Datura (Blakeslee 1921) it is well known that phenotypic differences between trisomics and the corresponding diploids are due to the change in genic balance brought about by the additional chromosome enabling identification of different trisomics on the basis of morphological characteristics. Tsuchiya $(1964,1967,1969)$ has described all the primary trisomics in wild and cultivated two-rowed barley. In the present study, trisomic plants were isolated approximately five weeks after germination when morphological differences from the normal plants were pronounced. Ovule sterility was higher than pollen sterility in the present trisomic plants. Trisomics of six-rowed barley obtained by Ramage (1960) were less fertile than those of Tsuchiya $(1964,1967,1969)$ in two-rowed barley. However, the present material showed fairly higher pollen and ovule fertility.

Meiotic behaviour of the chromosomes of the trisomic plants was, in general, similar to the trisomics obtained in barley and in other plants. The chromosome associations at metaphase $I$ and the types of trivalents observed are specific for primary trisomics. No cells were observed with a ring of three or a pentavalent which are the characteristic configurations of secondary and interchange-trisomics, respectively. In anaphasic separation the frequency of 7-8 separation was maximum. It is to be noted that 8-1-6 and 7-2-6 distributions were not found as observed by Das and Srivastava (1969) in interchange-trisomics. Though 9-6 separation was 8.24 per cent the progeny did not throw any nullisomic or tetrasomic plant as may be expected. This may be due to unstable gametes and low transmission through pollen and egg. These considerations lead, therefore, to conclude that the trisomic under study is a primary one.

The transmission rates through egg was 26.30 per cent. This agrees with the observations of Tsuchiya $(1958,1960)$. However, pollen transmission was nil. Trisomic plants were also found frequently in the progeny of selfed seeds. 
Large frequencies of trisomics were reported in the progeny of maize (Einset 1943) and barley. Ramage and Day (1960) suggested that for screening high frequency of primary and tertiary trisomics lighter seeds of interchange-heterozygotes may be used. The present study thus confirms that higher frequency of trisomes is obtained from lighter seeds.

Based on a study of the external morphology, Tsuchiya $(1958,1960)$ classified the trisomics into seven independent types. Das and Srivastava (1969) also on the basis of gross morphology identified trisomic plants arising from interchangeheterozygotes. The 12 primary trisomic lines in tomato were identified by Rick and Barton (1954) from pachytene analysis. On the basis of crosses with a set of translocation testers, the extra chromosome in the present trisomic was identified as chromosome 3. The description given by Tsuchiya of the trisomic for chromosome 3 'Pale' of the two-rowed barley is, however, somewhat different from what has been observed here. The leaves of the present trisomic were narrow and margins rolled. The ear heads were also narrow and spikelets were irregular. Morphological characteristics described by Das and Bhowmik (1971) in a six-rowed barley trisomic for chromosome 4 was also different from Tsuchiya's description of a 2-rowed trisomic for the same chromosome.

\section{Summary}

The trisomic plant isolated from gamma-irradiated barley material was phenotypically different from the normal diploid. The leaves of the trisome were narrow, margins rolled and light green in colour. Ear heads were also short, narrow and irregular. Ovule sterility ( 42.88 per cent) was relatively higher than pollen sterility (23.47 per cent).

Cytological examination at metaphase I revealed $6_{\mathrm{II}}+1_{\mathrm{III}}, 7_{\mathrm{II}}+1_{\mathrm{I}}$ and $66_{\mathrm{II}}+3_{\mathrm{I}}$. The trivalents were chains of 3 and V, Y, frying pan and $Q$ shaped indicating it to be a primary trisomic.

The trisome was crossed with a set of translocation homozygotes and the cytology of the $F_{1}$ hybrids was studied. This revealed that it was a trisomic for chromosome 3. However, the present trisomic looked different from the pale trisomic for chromosome 3 described by Tsuchiya in 2-rowed barley.

Trisomics occurred more frequently in the progeny of smaller seeds of trisomic plants. Transmission rate of the extra chromosome through ovule was high while it was nil through pollen.

\section{Bibliography}

Blakeslee, A. F. 1921. The Globe mutant in the Jimson Weed (Datura stramonium). Genetics 6: 241-264.

Das, K. and Bhowmik, G. 1971. A primary trisomic for chromosome 4 in a 6-rowed barley. Cytologia 36: 674-679.

- and Goswami, B. C. 1967. A note on translocation trisomic plant from gamma irradiated barley. Cytologia 19: 191-202. 
- and Srivastava, H. M. 1968. Trisomics from gamma irradiated barley. Paper presented at Indian Science Congress held in Varanasi, Jan. 3-9, 1968.

- and - 1969. Interchange trisomics in barley. Genetica 40: 555-565.

Einset, J. 1943. Chromosome length in relation to transmission frequency of maize trisomics. Genetics 28: 349-364.

Ramage, R. T. 1960. Trisomics from interchange heterozygotes in barley. Agron. J. 52: 156-159.

- and Day, A. D. 1960. Separation of trisomic and diploid barley seeds produced by interchange heterozygotes. Agron. J. 52: 590-591.

Rick, C. M. and Barton, D. W. 1954. Cytological and genetical identification of primary trisomics of tomato. Genetics 39: 640-666.

Tsuchiya, T. 1958. Studies on trisomics in Hordeum spontaneum C. Koch. Seiken Ziho 9: 69-86.

- 1960. Cytogenetic studies of trisomics in barley. Jap. Jour. Bot. 17: 177-213.

- 1964. Chromosome aberration and their use in genetics and breeding in barley. Trisomics and aneuploids. Barley Genetics 1: 116-150.

- 1967. The establishment of a trisomic series in a two-rowed cultivated variety of barley. Canad. J. Genet. and Cytol. 9: 667-682.

- 1969. Status of studies of primary trisomics and other aneuploids in barley. Genetica 40: 216-232. 